\title{
Identification of observables for future grids - the framework developed in the ELECTRA project
}

Visscher, Klaas; Marinelli, Mattia; Morch, Andrei Z. ; Jakobsson, Sigurd Hofsmo

Published in:

Proceedings of PowerTech 2015

Publication date:

2015

Document Version

Peer reviewed version

Link back to DTU Orbit

Citation (APA):

Visscher, K., Marinelli, M., Morch, A. Z., \& Jakobsson, S. H. (2015). Identification of observables for future grids - the framework developed in the ELECTRA project. In Proceedings of PowerTech 2015 IEEE.

\section{General rights}

Copyright and moral rights for the publications made accessible in the public portal are retained by the authors and/or other copyright owners and it is a condition of accessing publications that users recognise and abide by the legal requirements associated with these rights.

- Users may download and print one copy of any publication from the public portal for the purpose of private study or research.

- You may not further distribute the material or use it for any profit-making activity or commercial gain

- You may freely distribute the URL identifying the publication in the public portal

If you believe that this document breaches copyright please contact us providing details, and we will remove access to the work immediately and investigate your claim 


\section{Identification of observables for future grids - the framework developed in the ELECTRA project}

\author{
Klaas Visscher \\ Technical Sciences \\ TNO \\ Groningen, The Netherlands \\ Klaas.Visscher@tno.nl
}

\author{
Mattia Marinelli \\ Department of Electrical Engineering \\ DTU, Risø Campus \\ Roskilde, Denmark \\ matm@,elektro.dtu.dk
}

\author{
Andrei Z. Morch \\ Sigurd Hofsmo Jakobsson \\ Department of Energy Systems \\ SINTEF Energy Research \\ Trondheim, Norway \\ andrei.morch@sintef.no \\ sigurd.jakobsen@sintef.no
}

\begin{abstract}
The main subject of this paper is the classification and identification of observables for present and future grids. In order to make an inventory of present and potentially new observables, a systematic classification and identification of observables for future grids is conducted. After first introducing some fundamental definitions for observables, observables are further classified by the characteristic time scale where they are used in the physical power system. For actual use in control loops, observables must be part of so-called "Control Triples" consisting of control aim, observable, and system input signal. A survey of existing and potential Control Triples was conducted among partners in the European ELECTRA project, resulting in a spreadsheet inventory. The main findings are presented and a few major observability needs for realising the so-called "vertical integration" of control schemes reinforced by "horizontal integration" of distributed control schemes in the future grid.
\end{abstract}

Index Terms--Observable, control, future grids, smart grid.

\section{INTRODUCTION ${ }^{1}$}

The change from the present power system with central generation to a future system with distributed generation calls for a similar change in its control. The present power system is controlled vertically by TSOs and DSOs, as depicted in Figure 1.

In essence, this means that TSOs keep the power balance on a second to minutes time scale by monitoring the electric system frequency, thereby continuously compensating for power imbalances that are indicated by deviations from the nominal system frequency [6].

These immediate imbalances are kept minimal by following a power generation schedule in 15 minute time slots that would balance the day-ahead prediction of the system loads. Trading on Intraday market (Elbas) in the Nordic countries corrects the day-ahead schedule until one hour before the operation. An energy market where retailers buy or generate electric power and sell this to their customers at distributed load centres, ranging from

\footnotetext{
${ }^{1}$ The work described in this paper was conducted as part of the European ELECTRA project, grant: 609687, web site www.ElectraIRP.eu
}

industries to individual customers, determines the contribution of individual power plants to this generation schedule.

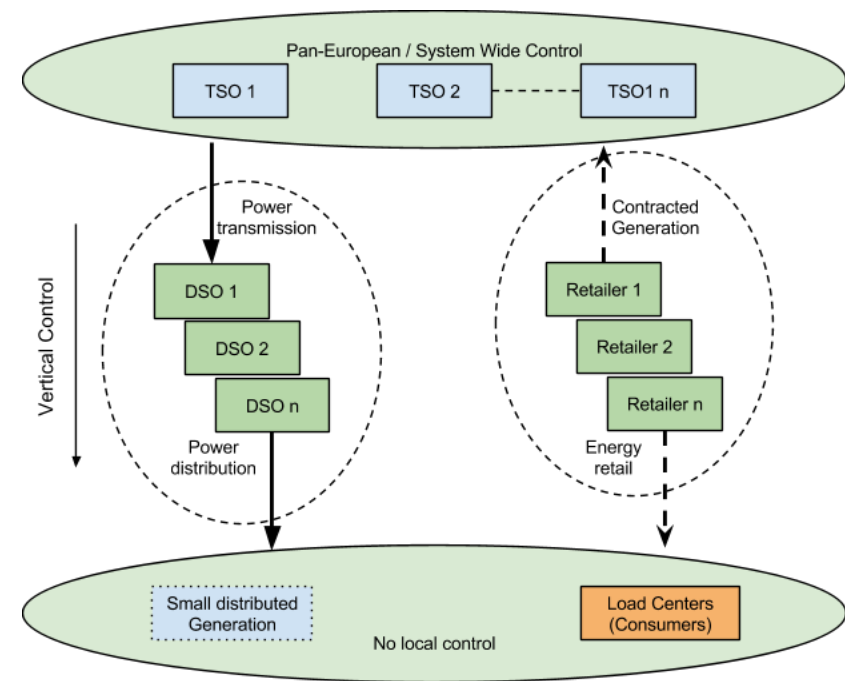

Figure 1. Vertical control in the present power system

DSOs distribute the power coming in from the transmission grid to their load centers, where local inabilities to transmit ample power are indicated by the deviations from nominal voltage in the involved substation nodes of their distribution system.

From a control system perspective, TSOs are able to keep the power balance because they can control a significant share (e.g., 90\%) of the total generation in the system. In the "Vertical Control Case" these are major synchronous generators in large power plants. Relatively small shares of intermittent RES generation (e.g., $10 \%$ in total, but more than $50 \%$ in Denmark in some days) in or near the load centers has little influence on the day-ahead prediction of the system load by consumers, and therefore little effect on the overall power system control and stability.

For three reasons this situation will be different in future power systems, where a significant share of generation is expected to come from decentralised generators distributed all over the power system. 
1. First of all a large part of generation cannot be controlled by the TSOs (e.g., 60\%), leaving them literally powerless to compensate for large deviations in the power balance, while small deviations would not pose a problem. Such a system may appear stable in normal operation, while sudden blackout may follow at any moment due to a large deviation. Still these large power imbalances in theory may be prevented using a correct day-ahead prediction of local generation in the distribution system, next to the already present day-ahead prediction of load centers.

2. The second reason now follows from the inconvenient truth that a lot of distributed generation is essentially intermittent, as it is driven by fickle weather conditions such as ambient temperature (e.g., CHP (Combined Heat and Power) plants), wind speed (e.g., wind farms) and solar irradiation (e.g., solar farms). There is no way to make a fairly reliable day-ahead prediction of such kinds of distributed generation yet. As unexpected imbalances due to intermittent generation happen on very short notice, this leaves the Intraday energy market empty handed to keep actual power imbalances small enough.

3. The third reason is that intermittent generation and intermittent demand at small industrial and even at household level is likely to become more coincident due to increased shares of EVs (Electric Vehicles), heat pumps, and small-scale generation as solar panels and micro-CHP devices. All of these devices show the nature to generate or demand at exactly or about the same time, either driven by weather conditions or by daily use patterns of customers. The coincident nature of these generators and loads may cause high power peaks resulting in overloads of cables, lines and transformers.

The conclusion from all this is that, in order to ensure reliable control over the power grid, also distributed generators and loads should be controlled in a way that increases the predictability of the maximum power imbalance as perceived system-wide by the TSOs.

Means to achieve that goal may be changing the topdown vertical control as depicted in Figure 1 into bidirectional "Vertically Integrated ${ }^{2}$ control schemes", comprising an exchange of global and local power balance and grid constraint information on a "need-to-know" basis, next to required control signals such as a desired change in total load, or generation or system inertia.

These "Vertical Integration control schemes" as such rely on the information to be aggregated and control signals to be effectuated on other local control schemes. The individual local control schemes must reduce the power imbalance within one characteristic time-scale, e.g. at TSO level (seconds to minutes), DSO level (minutes to

\footnotetext{
2 It must be noted here that the vertical integration does not imply that some control scheme on the pan-European level would directly control millions of low voltage devices on the distribution level at customer premises. Instead, communication between horizontal control algorithms only takes place on a "need-to-know basis", where the control algorithms operate on complementary time scales.
}

hours), Retail level (hours to days), Prosumer Aggregator level (minutes to hours) or Consumer/Prosumer level (minutes to hours). This type of control may be referred to as "Horizontally-Integrated control schemes".

Therefore, one could view the real time operation of future power systems as composed of "vertical integration" of control schemes reinforced by "horizontal integration" of distributed control schemes. This is depicted in Figure 2.
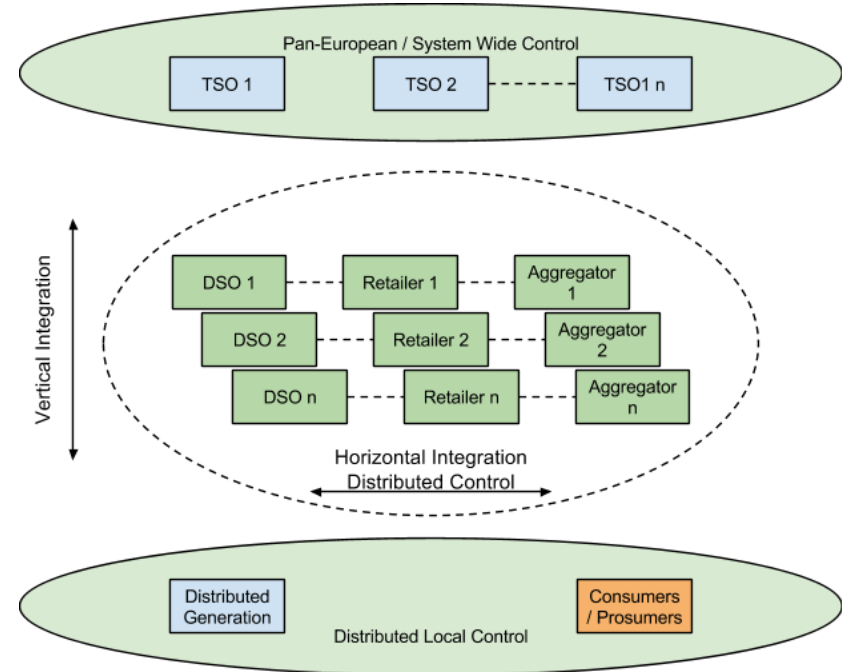

Figure 2. Vertical control reinforced with horizontal control

In conclusion, vertically-integrated control schemes reinforced with horizontally-distributed control schemes provide for a dynamic power balance that is closer to its equilibrium value than a conventional central control scheme. This enables grid operators to regain control in a future power system with a high share of decentralised generation in more efficient way than the conventional control systems.

Monitoring of the electricity network in the past was limited both by the lack of capable ICT technologies in combination with the fact that operation of the conventional vertical "downfall" power system did not necessarily require excessive monitoring, especially in the distribution network.

For a horizontal integration control scheme to work as intended, it must monitor at least some observable reflecting the local horizontal power imbalance. It may be clear that frequency deviation from nominal frequency cannot be a measure of local power imbalance, as that is a measure of the global power system imbalance only.

Therefore other observables are sought that do have a relevant relation to the local horizontal power imbalance. Examples of these are SOC (State of Charge) deviation from nominal in local energy storage, and power level deviations from circuit feeder set-points.

In order to make an inventory of present and potentially new observables, in this paper a systematic classification and identification of observables for future grids is conducted. First some fundamental "working 
definitions" for observables are introduced. For actual use in control loops, observables must be part of so-called "Control Triples" consisting of control aim, observable, and system input signal. As each control loops works on a certain time scale, the Control Triples are further classified by the characteristic time scale where they are used in the physical power system. Based on the survey results two Control Triple cases are discussed that may be of major importance for realising the "vertical integration" of control schemes reinforced by "horizontal integration" of distributed control schemes in the future grid.

\section{FUNDAMENTAL DEFINITIONS FOR OBSERVABLES}

\section{A. Basic definitions}

In this paragraph some basic definitions for observables in a physical (electric) system are given from a practical point of view. These may differ slightly from the definitions in highly mathematical control theory literature, as they are aimed at defining some practical measure of the quality of observables under consideration for use in control loops in the ELECTRA project.

\section{Physical System}

Figure 3 shows the basic relation between input signal and observable signal for a physical system. The next system description is based on a physical model to be chosen appropriately for the grid control problems to be solved.

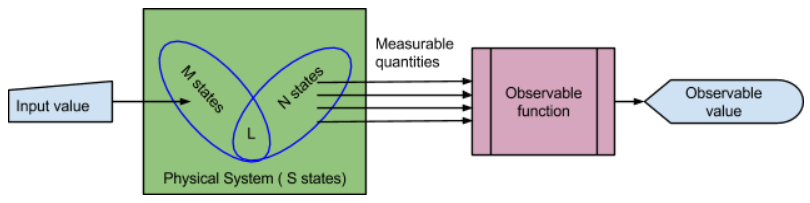

Figure 3 Relation between input signal and observable signal for a basic physical system model. Please note that the division in collections of potential states is not a spatial division, but a Venn diagram of collections.

The explanation of the diagram is as follows: states.

- A certain physical system model contains $\mathrm{S}$

- A certain input value to the system model influences $M$ system states.

- The observable function is a calculated function of a number of measurable quantities, which in turn depend on $\mathrm{N}$ system model states.

- The cross section of the collections of M states and $\mathrm{N}$ tates contains $\mathrm{L}$ system states. These $\mathrm{L}$ states are both influenced by the input value, and contribute to the observable value.

\section{System State}

A system state is defined as a collection of numbers completely describing the system model at a certain time ("snapshot").

- The actual system state is one element of the collection of S possible states.

\section{Observable}

An observable is a uniquely valued function of a number of measurable quantities in a physical system model .

- An observable can either be a scalar or vector ("State Vector") that relates to measured (observed) values in the present or past.

- An observable is calculated from measurements in the system.

Example: The RMS value of an AC voltage is an observable and so is the complex representation of an $\mathrm{AC}$ voltage. Both are computed or derived from an actual measured voltage as a function of time. The RMS voltage is a scalar, and the complex voltage is a vector.

With "actual value" of an observable we mean "derived from a time interval ranging from a short time in the past till now".

\section{Forecast ("Prediction")}

A forecast is a prediction of a future value of an observable.

- A forecast is not a physical observable, as its value does not exist yet, and therefore cannot be observed.

- Forecasts can be used to improve existing feedback control loops ("Predictive Control")

One may argue that predictions are also observables because mathematically their definitions cannot be distinguished. This argument may hold for mathematics, but it does not in physics. The reason is that mathematics allows travelling in time, while in physics we are stuck in the moment of time where we are now. In other words: It is not possible to go to the future in order to do physical measurements on basis of which future observable value are calculated.

\section{Measurement ("Observation")}

Source: IEEE Standards Definition Database [3]:

The raw data acquired by executing a test procedure.

It represents the observed characteristics of a specific signal (e.g., the voltage peak of a sinusoid waveform), the observed characteristics of the environment (e.g., the ambient temperature), or the derived value of product characteristics (e.g., the measured value of gain).

\section{ClaSSIFICATION OF OBSERVABLES}

\section{B. Transition time and Control Level}

In an effective control loop the elements of its Control Triple must work together on the same characteristic timescale. Therefore a classification of Control Triples can be made that is based on timescale. In the classical grid already a division by timescale is made in the so-called primary, secondary and tertiary control of system frequency. This division is derived from the system deployment time of its response and its control loops to switching events. This deployment time is further called the "Transition Time", which is defined here as: 
"Time for system response or system control loops to complete the transition from a stationary system state to the next stationary one, after a switching event occurs."

A "switching event" refers to any electrical connection in the system being opened or closed, either planned, deliberate (device on/off) or involuntary (short-circuit), thereby putting the system in an disturbed state for power, frequency and voltage. Next the system response and the control loops in the system determine how long it takes to restore the balanced state power, frequency and voltage, as well as to optimise the use of system resources. In order to make a division that is compatible with the classical grid frequency control loops, the Control Levels ${ }^{3}$ in the next table are chosen by Transition Time.

TABLE 1 Transition times and Control Levels

\begin{tabular}{|l|c|l|}
\hline \hline Control Level & $\begin{array}{c}\text { Transition time } \\
{[\mathbf{s}]}\end{array}$ & $\begin{array}{l}\text { Corresponding Classical } \\
\text { Control Level }\end{array}$ \\
\hline \hline 0.System response & 5 & 0.Inertial response \\
\hline 1.Primary Level & 30 & 1.Primary control \\
\hline 2.Secondary Level & 120 & 2.Secondary control \\
\hline 3.Tertiary Level & 900 & 3.Tertiary control \\
\hline
\end{tabular}

C. Survey of Control Triples

The Survey is built around the notion that every feasible control loop must have at least the set of three elements of a Control Triple:

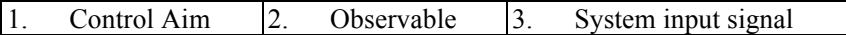

Its three elements cannot be chosen randomly by taking permutations of Control Aims, Observables and System input signals. First of all, these must be active at the same characteristic time scale (Control Level), as otherwise changes in one element value will not be perceived by the other two elements. Secondly a System input signal must influence states of the physical system (power grid) that cause changes of the Observable value. If these conditions are not met, then one essentially has a "broken" control loop that cannot function properly.

In order to keep an open mind, in a Control Triple the specific algorithm for calculating the observable is not specified yet. However this is necessary to make an actual control loop that can be implemented and tested. So for a certain Control Triple there would be a number of algorithms yielding similar observable values, thereby forming a number of control quadruples doing similar control jobs, but differing in Observability, Predictability and Controllability.

\section{Workflow of the Survey}

The workflow of the Survey of Control Triples is depicted in Figure 5. It starts by making separate lists for known and potential control aims, observables and system input signals, both taken from present practice and research projects [7-14]. These have no relation yet. Next

\footnotetext{
3 Although, some voltage controls, like the automatic voltage regulator on generators, generally act on a faster time scale than the frequency controls, we classify the voltage controls according to the same control levels. The rationale being that the transition times are an upper bound.
}

each of the lists is divided according to Control Levels. Now for each Control Level there are three independent lists of potential control aims, observables and system input signals, that still have no relation. In the last step, for each Control Level, meaningful Control Triples are chosen from the three independent lists of control aims, observables and system input signals, as explained in the paragraph on "Control Triples".

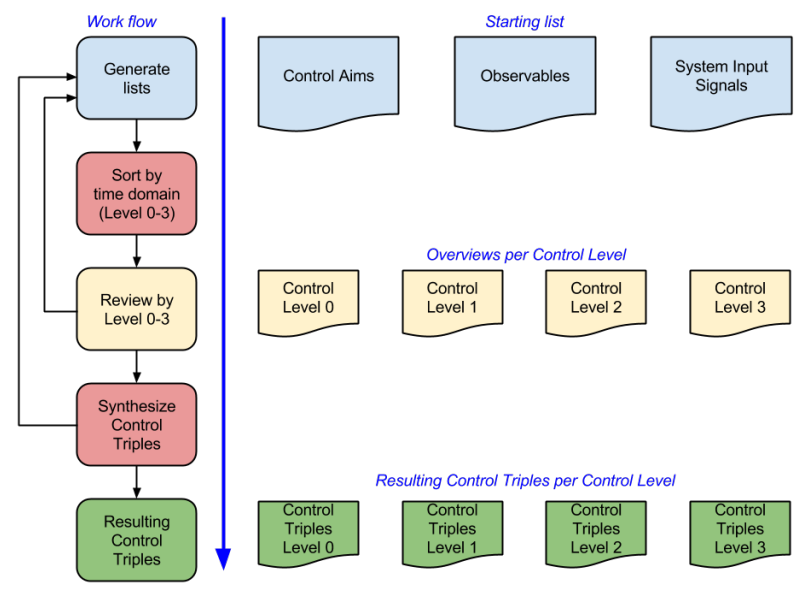

Figure 5 Workflow of the Survey

In order to correct errors of choice in the initial independent lists of control aims, observables and system input signals where necessary, two feedback loops are integrated in the process:

1. A review by Control Level, where a check is done whether all known control aims, observables and system input signals are listed and are compatible with the transition time by which the Control Level is defined.

2. A review by Control Level, where a check is done whether all meaningful Control Triples are listed that can be formed from the independent lists of control aims, observables and system input signals.

\section{E. Main results}

In order to smooth the process, the workflow shown is implemented in an automated spread sheet. The Control Triples have been chosen from existing practice or results from research projects referred to in the spread sheet [714]. A printout of this spread sheet is shown in "Annex I, Observability Fundamentals." of Deliverable D5.1 of the ELECTRA project [1].

In the next tables, the preliminary results are shown for the four Control Levels.

TABLE 2 Control Level Summary - 0.System response (5 s)

\begin{tabular}{|r|l|l|l|}
\hline Nr. & \multicolumn{1}{|c|}{ Control Aim } & \multicolumn{1}{|c|}{ Observable } & System Input Signal \\
\hline 1 & $\begin{array}{l}\text { Minimise current } \\
\text { distortion [A] }\end{array}$ & $\begin{array}{l}\text { Actual branch } \\
\text { current [A] }\end{array}$ & Injected current [A] \\
\hline 2 & $\begin{array}{l}\text { Minimise (stationary) } \\
\text { frequency fluctuations } \\
{[\mathrm{Hz}]}\end{array}$ & $\begin{array}{l}\text { Actual node } \\
\text { voltage [V] }\end{array}$ & $\begin{array}{l}\text { Inertial response } \\
\text { power [W] }\end{array}$ \\
\hline 3 & Minimise (stationary) & Actual node & Injected current [A] \\
\hline
\end{tabular}




\begin{tabular}{|l|l|l|l|}
\hline & voltage fluctuations [V] & voltage [V] & \\
\hline 4 & $\begin{array}{l}\text { Secure transient } \\
\text { frequency stability [Hz] }\end{array}$ & $\begin{array}{l}\text { Actual node } \\
\text { voltage [V] }\end{array}$ & $\begin{array}{l}\text { Inertial response } \\
\text { power [W] }\end{array}$ \\
\hline
\end{tabular}

TABLE 3 Control Level Summary - 1.Primary Level (30 s)

\begin{tabular}{|c|c|c|c|}
\hline Nr. & Control Aim & Observable & System Input Signal \\
\hline 1 & $\begin{array}{l}\text { Minimise current } \\
\text { deviations [A] }\end{array}$ & $\begin{array}{l}\text { Branch current } \\
\text { phasor }[\mathrm{A}]\end{array}$ & $\begin{array}{l}\text { Fast storage active and } \\
\text { reactive power [VA] }\end{array}$ \\
\hline 2 & $\begin{array}{l}\text { Minimise frequency } \\
\text { deviations }[\mathrm{Hz}]\end{array}$ & Frequency $[\mathrm{Hz}]$ & $\begin{array}{l}\text { Active power of } \\
\text { Synchronous Generator } \\
\text { [W] }\end{array}$ \\
\hline 3 & $\begin{array}{l}\text { Minimise reactive } \\
\text { current }[\mathrm{A}]\end{array}$ & $\begin{array}{l}\text { Complex power } \\
\text { [VA] }\end{array}$ & $\begin{array}{l}\text { Capacitor storage reactive } \\
\text { power [VA] }\end{array}$ \\
\hline 4 & $\begin{array}{l}\text { Minimise voltage } \\
\text { deviations [V] }\end{array}$ & $\begin{array}{l}\text { Node voltage } \\
\text { phasor }[\mathrm{V}]\end{array}$ & $\begin{array}{l}\text { Reactive power of } \\
\text { Synchronous Generator } \\
\text { [VA] }\end{array}$ \\
\hline 5 & $\begin{array}{l}\text { Secure power } \\
\text { transmission }[\mathrm{W}]\end{array}$ & $\begin{array}{l}\text { Node voltage } \\
\text { phasor }[\mathrm{V}]\end{array}$ & $\begin{array}{l}\text { Reactive power of } \\
\text { Synchronous Generator } \\
\text { [VA] }\end{array}$ \\
\hline 6 & $\begin{array}{l}\text { Minimise frequency } \\
\text { deviations }[\mathrm{Hz}]\end{array}$ & Frequency $[\mathrm{Hz}]$ & $\begin{array}{l}\text { On off signal of electrical } \\
\text { appliances }[0 / 1]\end{array}$ \\
\hline 7 & $\begin{array}{l}\text { Optimise microgrid } \\
\text { energy production } \\
\text { with storage devices } \\
{[\mathrm{Wh}]}\end{array}$ & Real Power [W] & $\begin{array}{l}\text { Active power of non- } \\
\text { rotating generator [W] }\end{array}$ \\
\hline
\end{tabular}

TABLE 4 Control Level Summary - 2.Secondary Level (120 s)

\begin{tabular}{|c|c|c|c|}
\hline r. & Control Aim & Observable & System Input Signal \\
\hline 1 & $\begin{array}{l}\text { Bring frequency back } \\
\text { to its set point }[\mathrm{Hz}]\end{array}$ & Frequency [Hz] & $\begin{array}{l}\text { Active power set point of } \\
\text { generators participating in } \\
\text { secondary control [W] }\end{array}$ \\
\hline 2 & $\begin{array}{l}\text { Enhance voltage } \\
\text { stability [V] }\end{array}$ & $\begin{array}{l}\text { Voltage error at } \\
\text { pilot nodes [V] }\end{array}$ & $\begin{array}{l}\text { Set point of AVRs of } \\
\text { generators [V] }\end{array}$ \\
\hline 3 & $\begin{array}{l}\text { Secure power balance } \\
\text { by generation }[\mathrm{W}]\end{array}$ & $\begin{array}{l}\text { Tie line power } \\
\text { flows [VA] }\end{array}$ & $\begin{array}{l}\text { Active power set point of } \\
\text { generators participating in } \\
\text { secondary control [W] }\end{array}$ \\
\hline 4 & $\begin{array}{l}\text { MV-LV transformer } \\
\text { and lines overloads } \\
\text { mitigation }[\mathrm{W}]\end{array}$ & $\begin{array}{l}\text { Current flowing } \\
\text { in the MV-LV } \\
\text { transformer [A] }\end{array}$ & $\begin{array}{l}\text { P,Q setpoint to DER } \\
{[\mathrm{W}, \mathrm{VA}]}\end{array}$ \\
\hline 5 & $\begin{array}{l}\text { LV network phase } \\
\text { balancing via } \\
\text { controllable DER } \\
\text { connected through a } \\
\text { PWM inverter }[1,2,3]\end{array}$ & $\begin{array}{l}\text { Current flowing } \\
\text { in the MV-LV } \\
\text { transformer [A] }\end{array}$ & $\begin{array}{l}\text { P,Q setpoint to DER } \\
{[\mathrm{W}, \mathrm{VA}]}\end{array}$ \\
\hline 6 & $\begin{array}{l}\text { LV overvoltages } \\
\text { management via } \\
\text { reactive dispatch of } \\
\text { DER in LV network } \\
{[\text { VA] }}\end{array}$ & $\begin{array}{l}1 \text { min averaged } \\
\text { voltage at the } \\
\text { end of the } \\
\text { feeder [V] }\end{array}$ & $\begin{array}{l}\text { P,Q setpoint to DER } \\
{[\mathrm{W}, \mathrm{VA}]}\end{array}$ \\
\hline 7 & $\begin{array}{l}\text { LV network phase } \\
\text { balancing via EV } \\
{[1,2,3]}\end{array}$ & $\begin{array}{l}1 \text { min averaged } \\
\text { voltage at the } \\
\text { customer } \\
\text { premises [V] }\end{array}$ & $\begin{array}{l}\text { EV charging phase } \\
\text { number }[1,2,3]\end{array}$ \\
\hline 8 & $\begin{array}{l}\text { LV overvoltages } \\
\text { management via } \\
\text { OLTC MV-LV trafo } \\
{[\mathrm{V}]}\end{array}$ & $\begin{array}{l}1 \text { min averaged } \\
\text { voltage at the } \\
\text { end of the } \\
\text { feeder [V] }\end{array}$ & OLTC setpoint [0-9] \\
\hline
\end{tabular}

TABLE 5 Control Level Summary -3.Tertiary Level (900 s)

\begin{tabular}{|r|l|l|l|}
\hline Nr. & \multicolumn{1}{|c|}{ Control Aim } & \multicolumn{1}{|c|}{ Observable } & \multicolumn{1}{|c|}{ System Input Signal } \\
\hline 1 & $\begin{array}{l}\text { Follow day-ahead } \\
\text { generation profile }[\mathrm{W}]\end{array}$ & $\begin{array}{l}\text { Secondary } \\
\text { reserve power } \\
{[\mathrm{W}]}\end{array}$ & $\begin{array}{l}\text { Start-up of generators } \\
\text { participating in tertiary } \\
\text { control [0/1] }\end{array}$ \\
\hline 2 & $\begin{array}{l}\text { Prevent overheating of } \\
\text { lines or cables (limit }\end{array}$ & $\begin{array}{l}\text { Core temperature } \\
\text { of line or cable }\end{array}$ & $\begin{array}{l}\text { Switch off industrial } \\
\text { loads participating in }\end{array}$ \\
\hline
\end{tabular}

\begin{tabular}{|l|l|l|l|}
\hline & temperature) $[\mathrm{K}]$ & {$[\mathrm{K}]$} & tertiary control [0/1] \\
\hline 3 & $\begin{array}{l}\text { Reduce deviation from } \\
\text { forecasted optimal } \\
\text { voltage values [V] }\end{array}$ & $\begin{array}{l}\text { Estimated } \\
\text { voltage at pilot } \\
\text { nodes [V] }\end{array}$ & $\begin{array}{l}\text { Set point of SVRs } \\
\text { (Secondary Voltage } \\
\text { Regulator) [V] }\end{array}$ \\
\hline 4 & $\begin{array}{l}\text { Prevent overheating of } \\
\text { transformers (limit } \\
\text { temperature) }[\mathrm{K}]\end{array}$ & $\begin{array}{l}\text { Core temperature } \\
\text { of transformer } \\
{[\mathrm{K}]}\end{array}$ & $\begin{array}{l}\text { Switch off distribution } \\
\text { station fields [0/1] }\end{array}$ \\
\hline
\end{tabular}

\section{POTENTIAL NEW OBSERVABLES}

Based on the spread sheet survey results in Tables 2 through 5, two Control Triple cases in the short time frames are discussed that may be of major importance for realising the "vertical integration" of control schemes reinforced by "horizontal integration" of distributed control schemes in the future grid.

\section{F. Inertial response power}

System frequency is often considered as an unambiguous parameter that is well defined. However this is only true for events on time scales that are multiples of 1 period of a pure voltage sine wave in the stationary system. For faster transients between stationary states and for amplitude variations the system frequency is no longer uniquely defined, as deviations from the pure sinusoidal wave can be explained both by amplitude variations and phase variations. There is no way to tell the difference.

However for a synchronous machine this ambiguity does not exist, as the momentary emf depends on the actual rotor speed only according to the Lenz law (emf = $\mathrm{d} \Phi / \mathrm{dt}$ ). At constant rotor speed an almost exact sinusoidal voltage is generated in the stator of a synchronous machine due to the revolving magnetic field of the rotor. When the rotor speed varies, both the frequency of the sine wave and its amplitude change, resulting in waveforms deviating from the sinusoidal shape.

A varying rotor speed implies a variation in rotor kinetic energy, which results in extra real power exchanges with the grid. At constant averaged rotor speed (and system frequency) these are zero on average. A temporarily diminishing rotor speed implies extra power delivered from the rotor to the grid, and a temporarily rising rotor speed implies extra power delivered by the grid to the rotor. So these real power exchanges counteract changes in grid frequency, thereby stabilising grid frequency, and is further called "inertial response power".

The inertial response mechanism described above is essential for system stability and protection, as it both keeps the power balance at very short times (milliseconds to seconds), and gives ample time to system protection measures to respond adequately. In the future grid it is expected that central synchronous machines with inertial power response will be replaced by solar and wind generation without inertial power response, thereby reducing the available inertial response power, resulting in potential frequency instability and failure of operators and protection measures to respond in time to incidents.

Therefore methods have to be sought to mimic inertial power response for solar and wind generation, thereby preserving normal operation. This is the purpose of 
Control Aim 2 "Minimise (stationary) frequency fluctuations [Hz]" in Table 2, with the observable "Actual node voltage [V]", and the system input signal "Inertial response power [W]". "Actual node voltage" means here that the actual voltage waveform progressing in time is the observable. A phasor representation (amplitude and phase) which has a time resolution of multiple full sine periods would not be detailed enough. The power delivered should resemble the inertial power response $\mathrm{P}_{\text {inertia }}$ [W] of a synchronous rotating mass with rotational speed $\omega$ and rotational inertia $\mathrm{J}\left[\mathrm{kg} \mathrm{m}^{2}\right]$, at rotational speed $\omega[\mathrm{rad} / \mathrm{s}]$ :

$$
P_{\text {inertia }}=-J \frac{d}{d t} \omega
$$

\section{Local Power Balance}

One of the ways to solve balancing problems due to intermittent generation is to minimise the local power imbalance for grid areas. The idea is that generated power should mainly be used locally in order to minimise losses, and to make the system imbalance as small as possible. This calls for an observable for the local power imbalance. Deviation from system frequency cannot be used for this purpose, as this is only a measure of the system wide power imbalance.

One way to do this is to apply the control aim 3 "Secure power balance by generation [W]" in Table 4, with observable "Tie line power flows [VA]" and system input signal". Active power set point of generators participating in secondary control [W]" to relatively small areas in the grid. The local power imbalance for such an area is the sum of the tie-line flows, and this can be minimised by controlling the active power setpoint of both local generators and loads. A disadvantage of this method is that it requires a very fast control in order keep the local balance within prescribed limits.

Another way is to directly control the tie-line flows. This can be achieved with grid elements like VFTs (Variable Frequency Transformers) [5] or PECs (Power Electronic Converters). A VFT is a version of a DFIG (Doubly Fed Induction Generator) which needs no power electronics. Therefore it does not produce harmonics and needs no separate filtering devices. A local energy store then makes up the for the immediate power imbalance. The deviation of its SOC (State of Charge) from nominal now is a direct measure for the local imbalance. Depending on the local control aims, the SOC can be controlled within prescribed limits, thereby giving the local operator and safety measures ample time to perform their task effectively. The control triple for this method would be "Secure local power balance [W]", with observable "SOC [1]" and system input signals "local generation and loads [W]".

\section{CONCLUSIONS}

A method for systematically identifying existing and potential control methods for future grids has been developed. It uses so-called "Control Triples" consisting of control aim, observable, and system input signal. As a control loops works on a certain time scale, the Control
Triples are further classified by the characteristic time scale where they are used in the physical power system.

A survey of existing and potential Control Triples was conducted among partners in the ELECTRA project [1], resulting in a spreadsheet inventory with more that 20 defined Control Triples, both classical and experimental, which are differentiated into four control levels according to their time scales. Two Control Triple cases are discussed that may be of major importance for realising the "vertical integration" of control schemes reinforced by "horizontal integration" of distributed control schemes in the future grid. Future work will consist in enriching the control triple set and applying them to the ELECTRA "Web of Cells" control concept [1].

\section{REFERENCES}

[1] "Adaptive Assessment of Future Scenarios and Mapping of Observability Needs", European ELECTRA project, grant: 609687 , WP5 "Increased Observability", Deliverable D5.1, www.ElectraIRP.eu

[2] Visscher, K. ; de Haan, S.W.H. , "Virtual synchronous machines (VSG's) for frequency stabilisation in future grids with a significant share of decentralized generation", SmartGrids for Distribution, 2008. IET-CIRED. CIRED Seminar, Publication Year: 2008, Page(s): 1 - 4

[3] IEEE Standards Definition Database, http://dictionary.ieee.org/

[4] The Wikibook of: "Control Systems and Control Engineering" http://en.wikibooks.org/wiki/Control_Systems

[5] F. I. Bakhsh and D. K. Khatod, "Variable Frequency TransformerState of the art review," in Energy Efficient Technologies for Sustainability (ICEETS), 2013 International Conference on, 2013, pp. 1012-1017.xx

[6] Load-Frequency Control and Performance Policy, https://www.entsoe.eu/fileadmin/user_upload/_library/publications/ entsoe/Operation_Handbook/Policy_1_final.pdf

[7] EcoGrid EU: From Design to implementation. A large scale demonstration of a real-time marketplace for Distributed Energy Resources. Project Report 2014. http://www.eu-ecogrid.net/rssfeed/55-new-ecogrid-eu-report-from-design-to-implementation

[8] Van, T.V.; Visscher, K.; Diaz, J.; Karapanos, V.; Woyte, A.; Albu, M.; Bozelie, J.; Loix, T.; Federenciuc, D., Virtual synchronous generator: An element of future grids, Innovative Smart Grid Technologies Conference Europe (ISGT Europe), 2010 IEEE PES, ISBN 978-1-4244-8508-6

[9] The Cell Controller Pilot Project (CCPP), Public Report. Energinet.dk 2011.

[10] STRONGrid - Smart Transmission Grids Operation and Control http://www.kth.se/en/ees/omskolan/organisation/avdelningar/eps/res earch/smarttslab/projekt-smartslab/strongrid-1.461968

[11] OPTIMATE - An Open Platform to Test Integration in new MArkeT designs of massive intermittent Energy sources dispersed in several regional power markets, http://www.optimateplatform.eu/

[12] P. B. Andersen, M. Marinelli, O. J. Olesen, G. Poilasne, B. Christensen, C. Amstrup, and O. Alm, "The Nikola Project: Intelligent Electric Vehicle Integration", Innovative Smart Grid Technologies (ISGT Europe), 2014 5th IEEE PES International Conference and Exhibition on, pp.1-5, Istanbul, 12-15 Oct. 2014

[13] M. Coppo, M. Marinelli, X. Han, and R. Turri, "Voltage Management in Unbalanced Low Voltage Networks Using a Decoupled Phase-Tap-Changer Transformer," Universities Power Engineering Conference (UPEC), 2014 Proceedings of the 49th International, pp.1-6, Cluj Napoca, 2-5 Sep. 2014.

[14] M. Marinelli, F. Sossan, G. T. Costanzo, and H. W. Bindner, "Testing of a Predictive Control Strategy for Balancing Renewable Sources in a Microgrid," Sustainable Energy, IEEE Transactions on, vol. 5, no. 4, pp. 1426-1433, Oct. 2014. 